\title{
Ocorrências de desastres naturais na região do Cariri paraibano
}

\author{
Occurrences of natural disasters in the Cariri paraibano \\ SÉRGIO $^{1}$, M, A, S.; ARAÚJO ${ }^{1}$, M, O. L.; MOURA² ${ }^{2}$ M, O. \\ matheus_sergio@hotmail.com
}

\begin{abstract}
Resumo
A presente pesquisa analisou as ocorrências de desastres de ordem hidrometeorológica e climática na região do Cariri paraibano entre os anos de 2003 a 2016 com o intuito de verificar a distribuição espaço-temporal destas ocorrências. Os dados utilizados para a realização desta pesquisa foram adquiridos nos sites do Ministério da Integração Nacional (MI) e no Sistema Integrado de Informações sobre Desastres, também ligado ao MI. Os resultados obtidos foram representados através de recursos gráficos, além de mapas temáticos desenvolvidos por meio de SIG (Sistema de Informação Geográfica). Na região estudada foram registrados 604 reconhecimentos de desastres, desses, 548 foram reconhecidos por SE (Situação de Emergência) e 56 por ECP (Estado de Calamidade Pública). A maior parte das portarias reconhecidas foram oriundas das Secas/Estiagem.
\end{abstract}

Palavras-chave: Desastres Climáticos. Desastres Hidrometeorológicos. Situação de emergência. Estado de Calamidade Pública.

\begin{abstract}
The present study analyzed the occurrences of hydrometeorological and climatic disasters in the Cariri region of Paraíba between the years 2003 and 2016 in order to verify the spatial and temporal distribution of these occurrences. The data used to carry out this research were obtained from the websites of the Ministry of National Integration (MI) and the Integrated Disaster Information System, also linked to the MI. The results obtained were represented through graphic resources, as well as thematic maps developed through GIS (Geographic Information System). In the region studied, 604 disasters were registered, of which 548 were recognized by SE (State of Emergency) and 56 by ECP (State of Public Calamity). Most of the recognized ordinances came from Droughts/Dry.
\end{abstract}

Keywords: Climate Disasters. Hydrometeorological Disasters. Emergency situation. State of Public Calamity.

\section{INTRODUÇÃO}

A temática dos desastres naturais está muito presente no universo acadêmico inclusive, na ciência geografia. A capacidade de correlacionar os impactos físicos e humanos que os desastres causam é competida ao Geógrafo, que desde sua formação, busca compreender os prejuízos em ambas as áreas.

"Nas últimas décadas os desastres naturais têm se tornado tema cada vez mais presentes no cotidiano das populações, há um aumento considerável tanto na frequência quanto na intensidade desses fenômenos" (JUNGLES, 2012, p. 4). O aceleramento da urbanização, a ocupação de ambientes frágeis e a exploração dos recursos naturais acima da capacidade suportada são alguns dos fatores que contribuem para o acontecimento dos desastres.

A região do Nordeste Brasileiro (NEB) é a mais afetada com a ocorrência de desastres naturais, detendo cerca de 57,3\% de um total de 25.943 de desastres ocorridos no país no período de 2003 à 2015 (MOURA et. al., 2016 p. 5), sendo que os maiores números desses reconhecimentos encontram-se no estado da Paraíba, totalizando 2.983 desastres reconhecidos, onde 94,43\% (2.816)

\footnotetext{
${ }^{I}$ Matheus Alexandre de Souza Sérgio, Departamento de Geociências, Universidade Federal da Paraíba, Caicó-RN, Brasil.

${ }^{I}$ Maressa Oliveira Lopes Araújo, Departamento de Geociâncias, Universidade Federal da Paraíba, Caicó-RN, Brasil.

${ }^{2}$ Marcelo de Oliveira Moura, Departamento de Geociências, Universidade Federal da Paraíba, Caicó-RN, Brasil.
} 
são decretos de Situação de Emergência (SE) e 5,57\% (167) de Estado de Calamidade Pública (ECP) (MOURA et. al, 2017 p. 4). Diante do exposto, levanta-se a hipótese que a região do cariri paraibano é no Estado da Paraíba a região mais crítica em relação a frequência de reconhecimento de desastres naturais, em especial, aqueles de ordem climáticas (estiagem/seca).

O principal objetivo desse artigo é levantar e analisar a distribuição espaço-temporal dos desastres naturais de ordem hidrometeorológica e climática ocorridos na região do Cariri paraibano no período de 2003 a 2016. Esse objetivo atende uma das demandas do projeto de pesquisa do Laboratório de Climatologia Geográfica (CLIMAGEO) da Universidade Federal da Paraíba intitulado "Desastres naturais associados a dinâmica climática no estado da Paraíba, 2003 a 2016”.

\section{METODOLOGIA}

Para o desenvolvimento do trabalho foram adquiridos os dados por meio de planilhas que continham informações de reconhecimentos de SE e ECP realizados para o Estado da Paraíba.de reconhecimento dos desastres naturais no site do Ministério da Integração Nacional (MI). Dessas planilhas foram extraídos os reconhecimentos realizados para a área de estudo, disponíveis em: http://www.mi.gov.br/reconhecimentos-realizados. Em uma etapa posterior a foram adquiridos informações sobre os danos humanos, materiais e ambientais gerados pelos desastres naturais. Essas informações foram extraídas nos Formulários de Avaliação de Danos (AVADAN) e no Formulário de Informações de Desastres Naturais (FIDE) disponibilizados na plataforma S2ID também pertencente ao MI, disponíveis em: https://s2id.mi.gov.br/. A escala temporal utilizada no trabalho é de 2003 a 2016, pois é só a partir do ano de 2003 que o Ministério da Integração disponibiliza os dados.

Os dados foram representados em mapas temáticos, confeccionados em ambiente SIG, referentes a SE e ECP. Somado a isso foram desenvolvidos gráficos para representar as informações sobre os danos humanos e materiais, além dos totais anuais e de distribuição dos desastres por intensidade e por tipo.

\section{3. ÁREA DE ESTUDO}

A região do Cariri Paraibano faz parte da divisão realizada por Silva (2007 p. 45) que contemplou a Paraíba com 6 microrregiões que possuem em seus municípios uma semelhança pluviométrica (Mapa 1). 


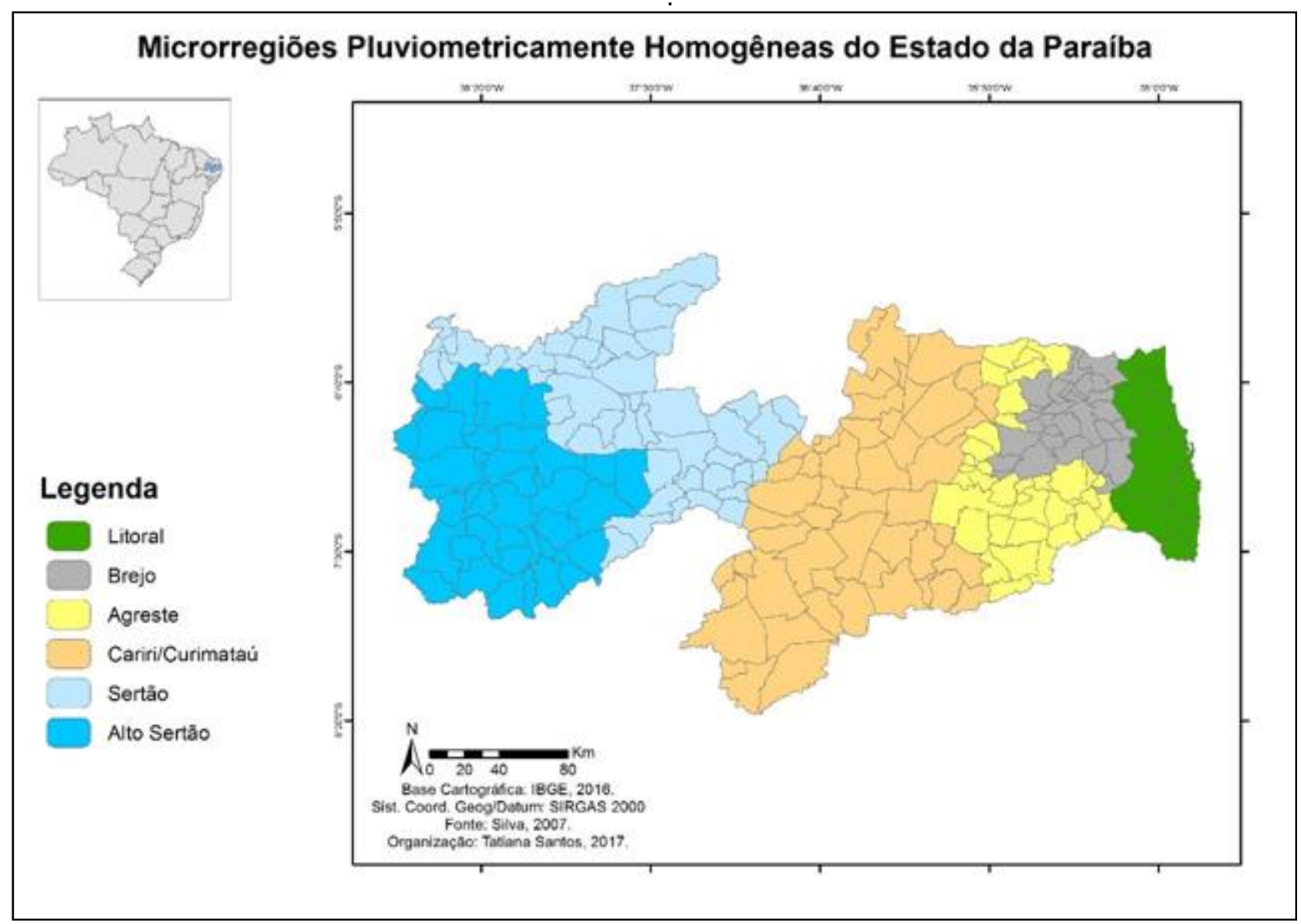

Figura 1 - Divisão pluviometricamente homogênea do Estado da Paraíba Fonte: Silva (2007) Organização: Tatiana Santos (2017)

Inicialmente o trabalho estudaria a microrregião do Cariri/Curimataú, conforme foi proposto por Silva (2007, p.45), porém a área foi redimensionada, passando a se trabalhar apenas com a região do Cariri, não havendo qualquer prejuízo na pesquisa tendo em vista que as condições climáticas, em especial, o regime das chuvas, são semelhantes entre as regiões definidas por Silva (2007, p.45).

A microrregião está localizada na parte Centro-Sul do Estado da Paraíba e segundo o censo de 2010 possui um total de 218.737 habitantes. É compreendida por 33 municípios (Figura 2), são elas: Alcantil, Amparo, Assunção, Barra de Santana, Barra de São Miguel, Boa vista, Boqueirão, Cabaceiras, Camalaú, Caraúbas, Caturité, Congo, Coxixola, Gurjão, Junco do Seridó, Livramento, Monteiro, Ouro Velho, Parari, Prata, Riacho de Santo Antônio, Salgadinho, Santa Cecília, Santo André, São Domingos do Cariri, São João do Cariri, São João do Tigre, São José dos Cordeiros, São Sebastião do Umbuzeiro, Serra Branca, Sumé, Taperoá e Zabelê. 


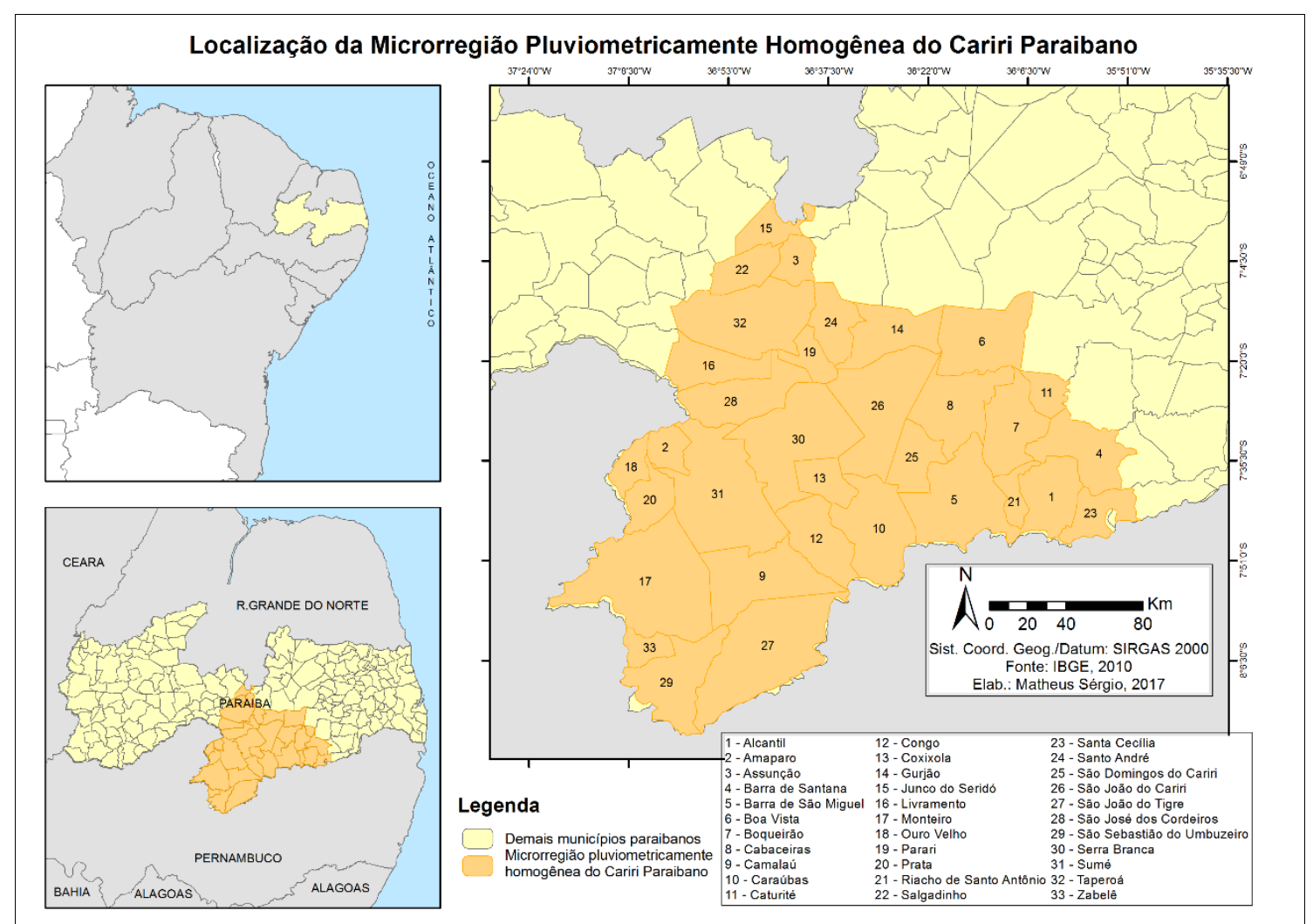

Figura 2 - Mapa de localização da região do Cariri Paraibano. Fonte: Autor, 2017.

O clima da microrregião é semiárido e se caracteriza pela alta incidência de luz solar, superior a 2800 horas anuais e uma média de temperatura de $26^{\circ} \mathrm{C}$, além de um índice pluviométrico baixo e muito mal distribuído temporalmente podendo variar de $400 \mathrm{~mm}$ a 600mm/ano, a região também possui o município considerado o mais seco do Brasil, Cabaceiras, que chega a registrar um índice pluviométrico anual de 246mm (NASCIMENTO e ALVES, 2008, p.28). O referido município sofre os efeitos orográficos do Planalto da Borborema, assim, a escassez das chuvas é um fator limitante as atividades econômicas, que sobrevivem da caprinocultura, e numa insipiente agricultura fundamentada no cultivo da palma para alimentar rebanho (LIMEIRA, 2008, p.40). O período chuvoso da região se dá nos meses de janeiro a maio graças à atuação do sistema meteorológico Zona de Convergência Intertropical (ZCIT) e o período seco vai de junho a dezembro.

\section{RESULTADOS E DISCUSSÃO}

De acordo com a Secretaria Nacional de Defesa Civil (SEDEC) na região pluviométrica do Cariri paraibano, entre os anos de 2003 e 2016, foram reconhecidos um total de 604 desastres, desses, 548 foram reconhecidos por meio de SE e 56 por meio de ECP, sendo a grande maioria desses desastres oriundos das secas e estiagens ocorridas na microrregião. 
O número total de desastres naturais ocorridos na região do Cariri paraibano é representado pelo Gráfico 1. Observa-se que o ano que mais apresenta ocorrências é o ano de 2013 (99 ocorrências) e o que menos apresenta é o de 2011 (5 ocorrências).

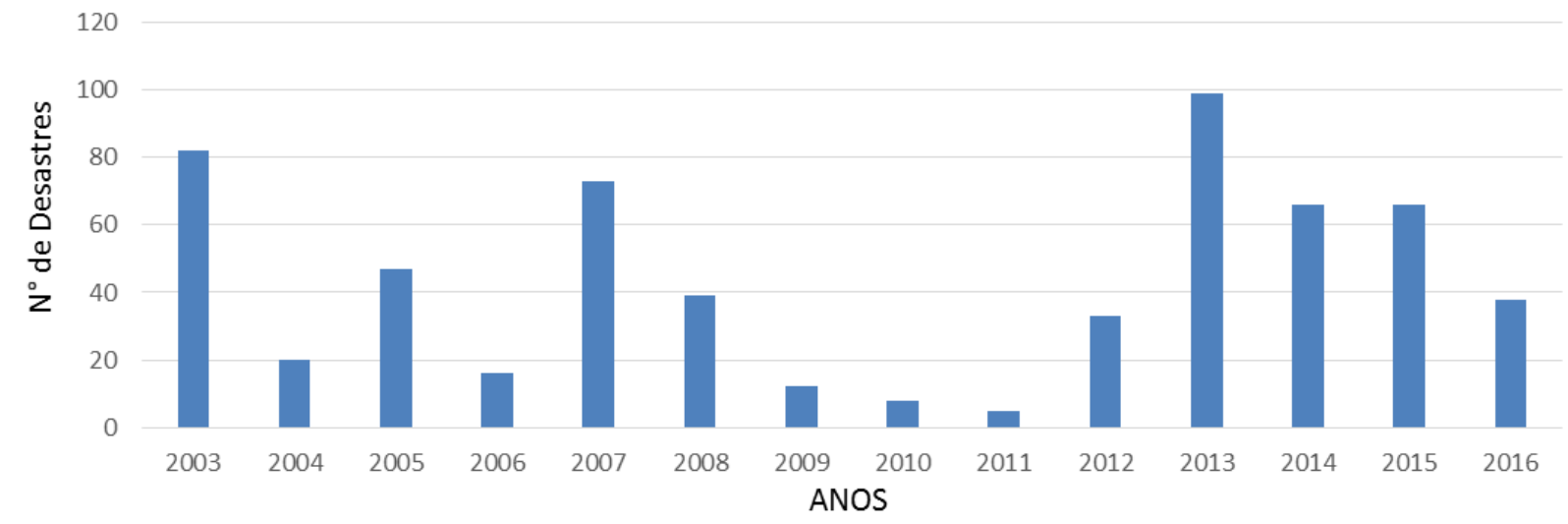

Gráfico 1 - Número de ocorrências dos desastres hidrometeorológicos e climáticos. Fonte: Brasil, 2016

O Gráfico 2 representa o número de desastres subdivido por tipos, são eles: estiagem/seca, enxurradas, chuvas intensas e enchentes. A microrregião do Cariri paraibano apresentou o maior número de desastres naturais oriundos da estiagem/seca, o que pode se justificar pela média pluviométrica da microrregião que não supera os 600mm (Sena 2012 apud Beserra, 2013, p. 1403), sendo o ápice dos acontecimentos no ano de 2013, onde foram registrados 99 desastres oriundos da seca/estiagem e o ano que menos apresentou registros foi o ano de 2011, sendo estes 3 enchentes, 1 enxurrada e uma estiagem.

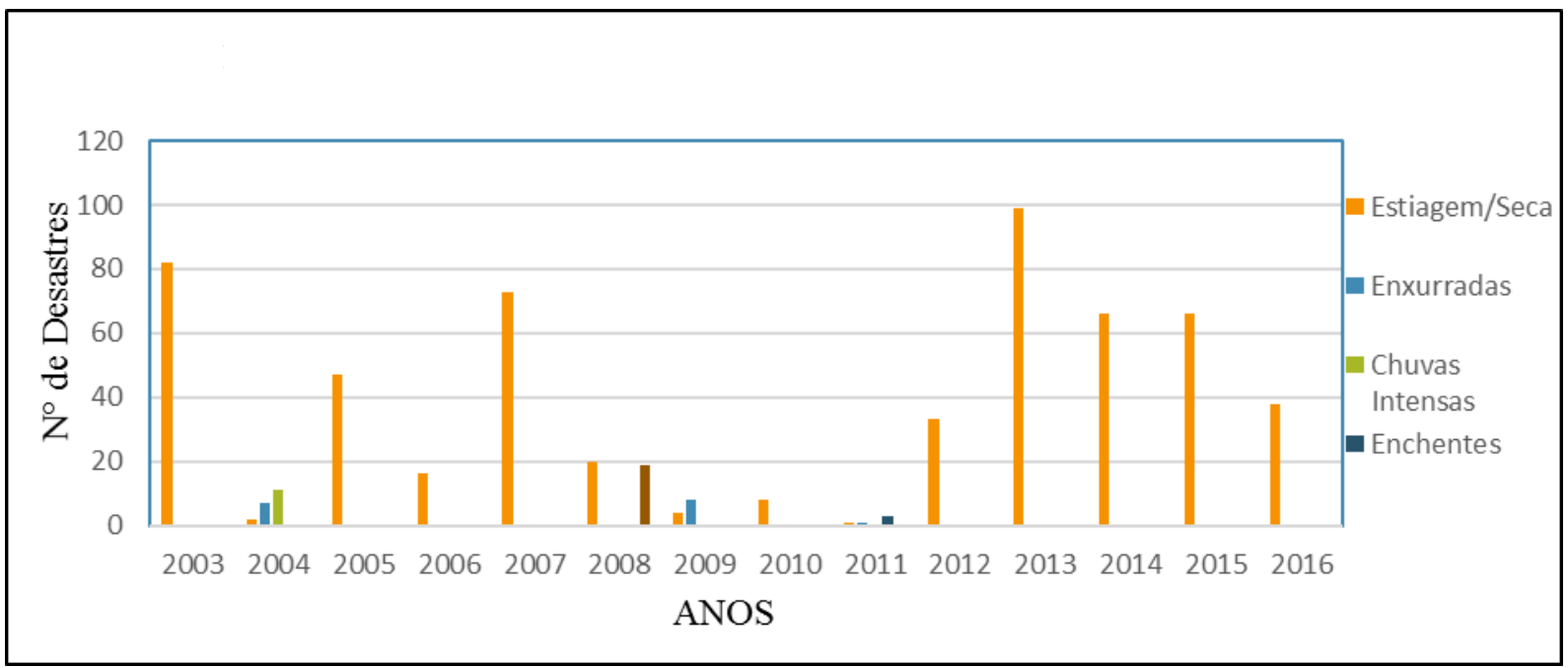

Gráfico 2 - Distribuição anual por tipo de desastre na região do Cariri paraibano, 2003 a 2016.

Na prancha 1 estão representados os desastres de ordem climática (Seca/Estiagem) que tiveram suas portarias reconhecidas por meio de Situação de Emergência. Todos os municípios 
apresentaram ocorrências de Secas/Estiagem, sendo Alcantil o município que mais apresentou reconhecimentos, foram 18 no total e São Domingos do Cariri o que menos apresentou reconhecimentos, 12 no total.
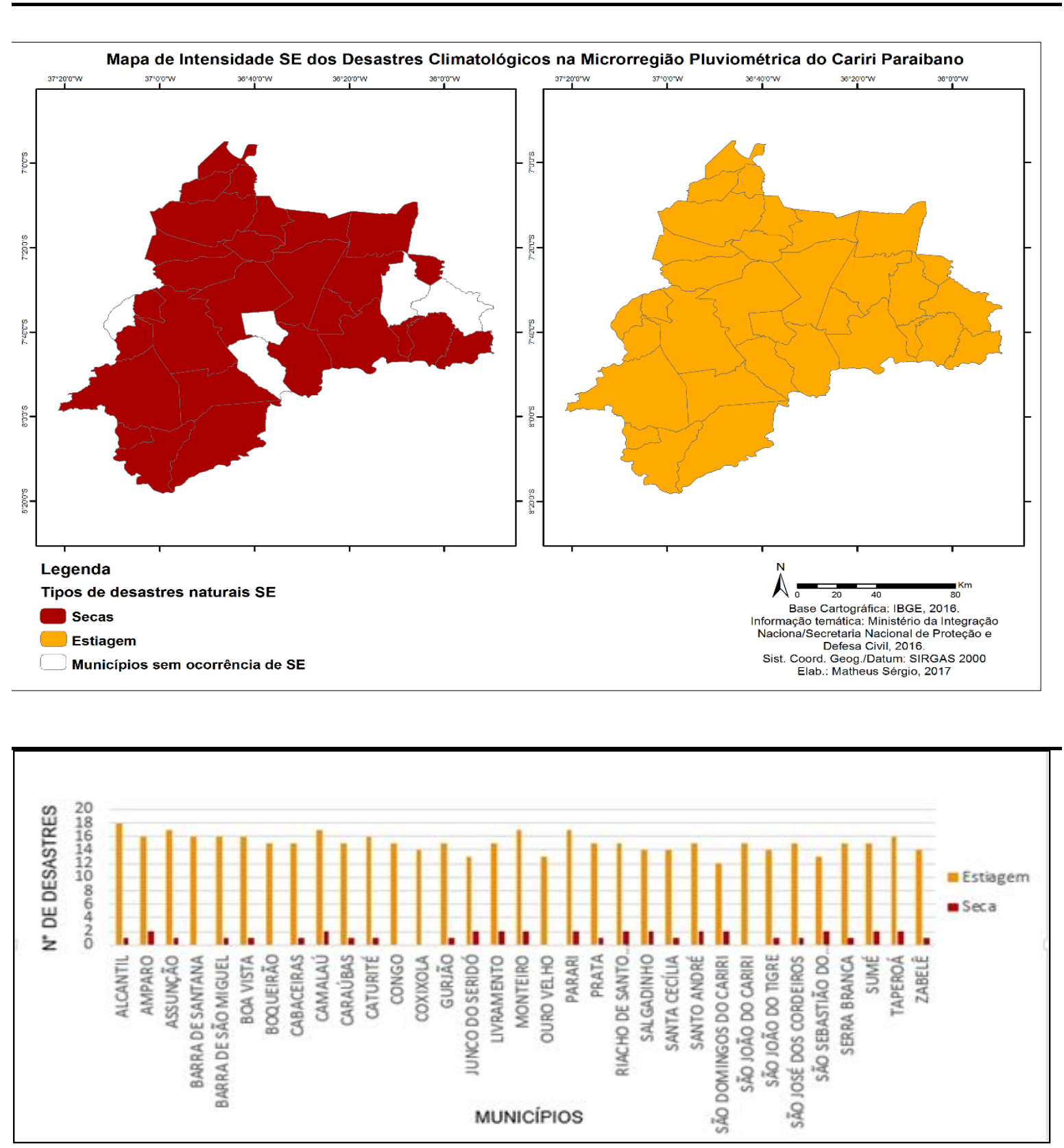

Prancha 1 - Intensidade dos desastres climáticos na região do Cariri paraibano SE. Fonte: SEDEC, 2016 Organização: Autor, 2017

$\mathrm{Na}$ prancha 2 estão também representados os desastres de ordem climática, porém, que tiveram suas portarias reconhecidas por meio de Estado de Calamidade Pública (ECP). Os municípios variaram entre 1 e 2 reconhecimentos. Apenas os municípios de Coxixola e São José dos Cordeiros não realizaram reconhecimentos de ECP. 

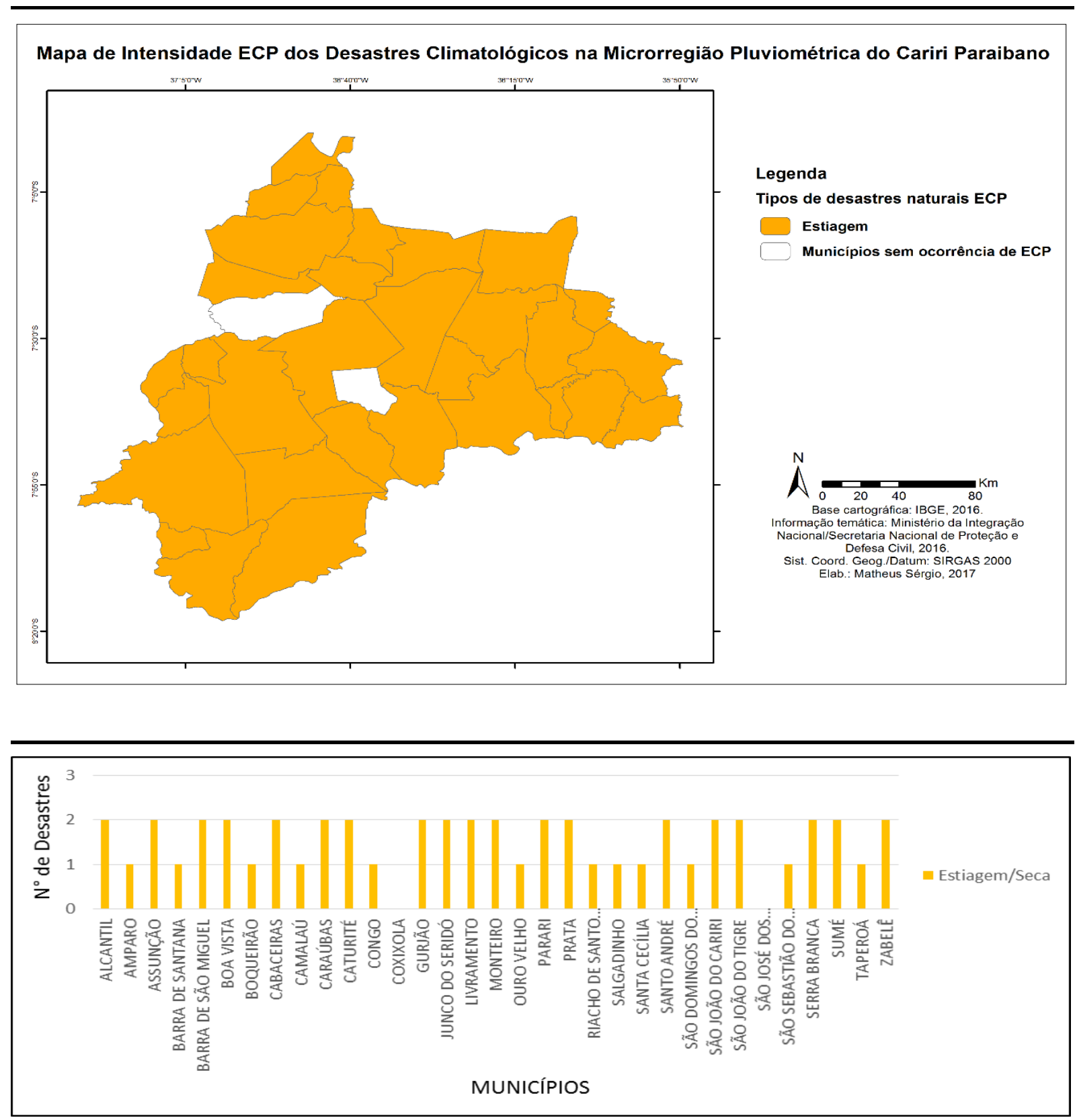

Prancha 2 - Intensidade dos desastres climáticos na região do Cariri paraibano ECP. Fonte: SEDEC, 2016 Organização: Autor, 2017.

Na prancha 3 estão representados os desastres de ordem hidrometeorológica reconhecidos por meio de SE. Os desastres hidrometeorológicos na região do Cariri ocorreram nos anos de 2004, 2008 e 2009. 

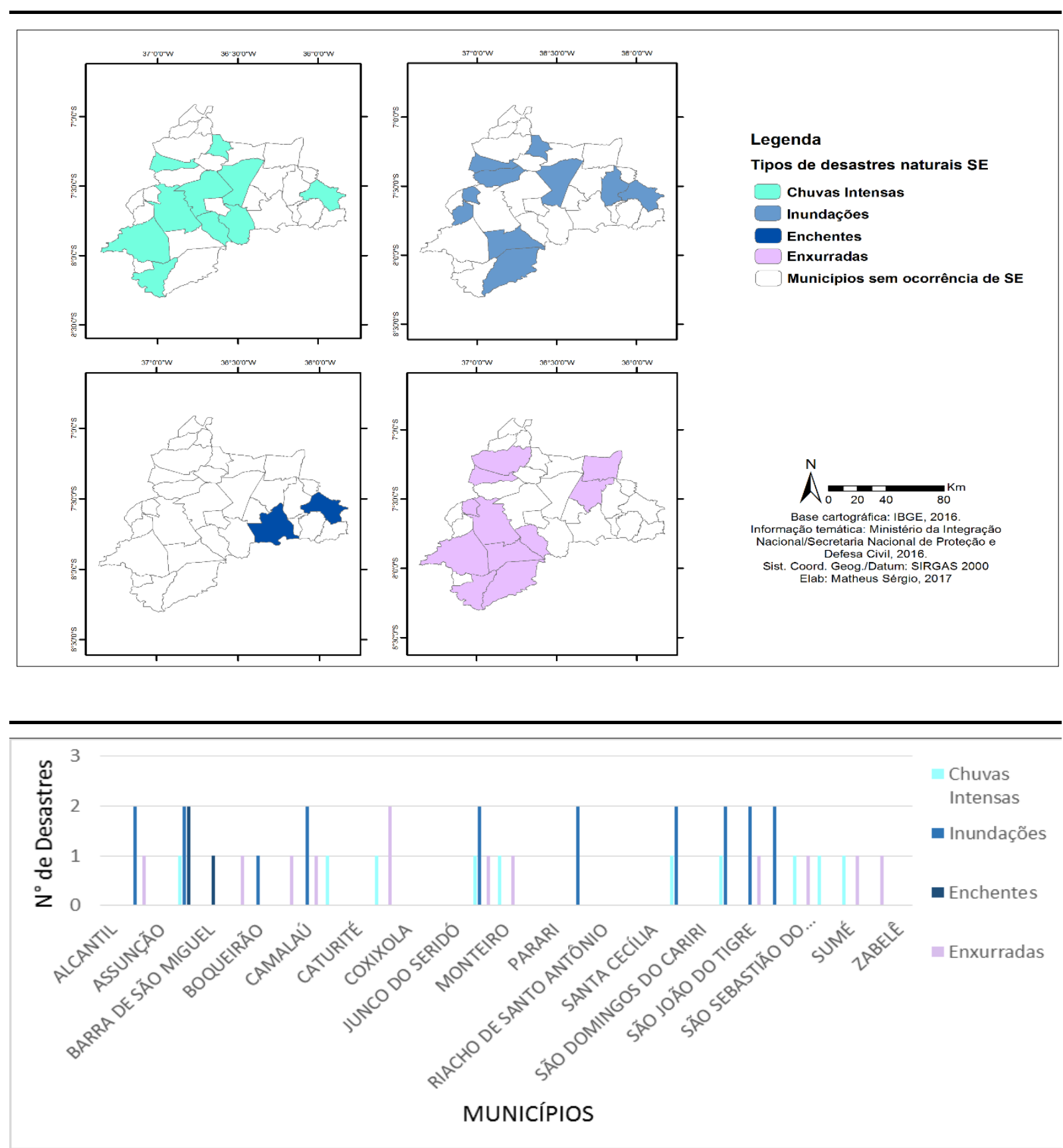

Prancha 3 - Intensidade dos desastres hidrometeorológicos na região do Cariri paraibano SE. Fonte: SEDEC, 2016 - Organização: Autor, 2017.

$\mathrm{Na}$ prancha 4 foram também representados os desastres de ordem hidrometeorológica com reconhecimentos realizados através de ECP. Os desastres ocorreram no ano de 2004 e foram do tipo enxurrada. Os municípios de Assunção, Junco do Seridó, São João do Tigre e São José dos Cordeiros realizaram 1 reconhecimento cada. 

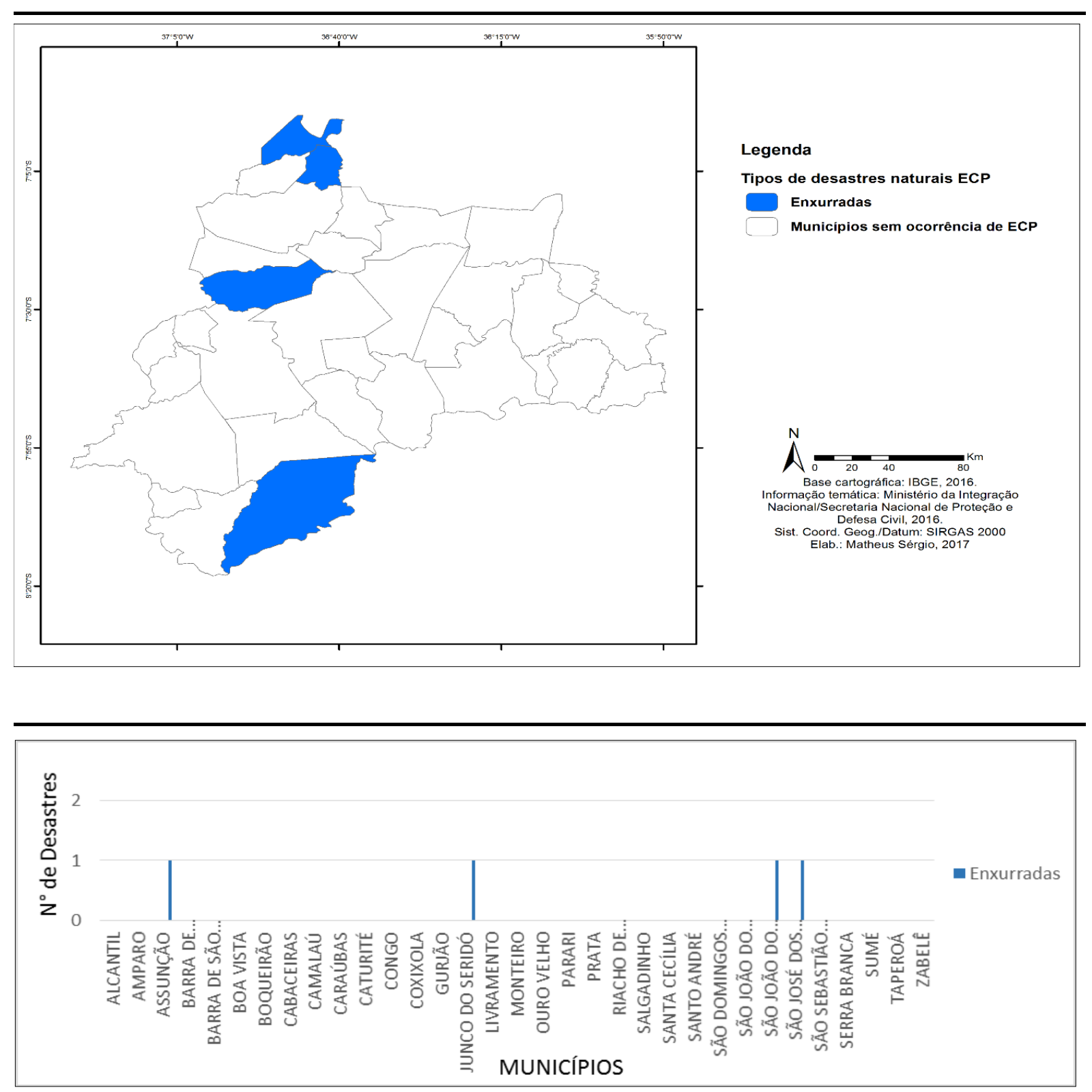

Prancha 4 - Intensidade dos desastres hidrometeorológicos na região do Cariri paraibano ECP. Fonte: SEDEC, 2016 - Organização: Autor, 2017.

Um dos principais problemas encontrados no desenvolvimento da pesquisa foi a falta de formulários correspondentes aos desastres reconhecidos (Quadro 1). Dos 604 desastres naturais registrados na região, apenas 314 (52,5\%) possuem formulários que possibilitam a análise dos danos. Vale salientar que os anos de 2012, 2013, 2014 e 2015, apresentaram formulários não preenchidos, o que impossibilitou a análise dos dados. 


\begin{tabular}{|c|c|c|}
\hline \multicolumn{3}{|c|}{ Relação entre número de reconhecimentos e formulários disponíveis } \\
\hline ANOS & $\begin{array}{c}\text { NÚMERO DE } \\
\text { RECONHECIMENTOS }\end{array}$ & $\begin{array}{l}\text { FORMULÁRIOS } \\
\text { DISPONÍVEIS }\end{array}$ \\
\hline 2003 & 82 & 36 \\
\hline 2004 & 20 & 18 \\
\hline 2005 & 47 & 29 \\
\hline 2006 & 16 & 16 \\
\hline 2007 & 73 & 43 \\
\hline 2008 & 39 & 21 \\
\hline 2009 & 12 & 10 \\
\hline 2010 & 8 & 7 \\
\hline 2011 & 5 & 0 \\
\hline 2012 & 33 & $\begin{array}{c}1 \\
\text { (SEM INFORMAÇÃO) }\end{array}$ \\
\hline 2013 & 99 & $\begin{array}{c}1 \\
\text { (SEM INFORMAÇÃO) }\end{array}$ \\
\hline 2014 & 66 & $\begin{array}{c}66 \\
\text { (SEM INFORMAÇÃO) }\end{array}$ \\
\hline 2015 & 66 & $\begin{array}{c}66 \\
\text { (SEM INFORMAÇÃO) }\end{array}$ \\
\hline 2016 & 38 & 0 \\
\hline TOTAL & 604 & 314 \\
\hline
\end{tabular}

Quadro 1 - Relação entre o número de reconhecimentos e os formulários disponíveis. Fonte: SEDEC, 2016. Organização: Autor, 2017.

\subsection{Análise das áreas afetadas e dos danos}

Neste subitem da pesquisa serão elencados todos os danos causados pelos desastres, vale salientar, como já dito anteriormente, que nem todos os desastres reconhecidos pela SEDEC possuíam formulários disponíveis no sistema S2ID, portanto, todos os danos representados são oriundos dos formulários disponíveis no sistema.

Os danos humanos causados pelos desastres naturais afetaram, no mínimo, 610.356 pessoas entre o período de 2003 a 2016, conforme mostra o quadro 2. Observa-se que o ano de 2003 foi o que apresentou o maior número de pessoas afetadas (202.401 pessoas) e o ano de 2009 o que menos 
apresentou (18.921 pessoas). Ressalta-se, novamente, a problemática da falta de dados para se completar a análise completa da escala temporal.

\begin{tabular}{|c|c|}
\hline ANOS & $\begin{array}{c}\text { PESSOAS } \\
\text { AFETADAS }\end{array}$ \\
\hline $\mathbf{2 0 0 3}$ & 202.401 \\
\hline $\mathbf{2 0 0 4}$ & 19.744 \\
\hline $\mathbf{2 0 0 5}$ & 92.466 \\
\hline $\mathbf{2 0 0 6}$ & 46.570 \\
\hline $\mathbf{2 0 0 7}$ & 142.207 \\
\hline $\mathbf{2 0 0 8}$ & 61.183 \\
\hline $\mathbf{2 0 0 9}$ & 18.921 \\
\hline $\mathbf{2 0 1 0}$ & 26.864 \\
\hline $\mathbf{2 0 1 1}$ & 0 \\
\hline $\mathbf{2 0 1 2}$ & 0 \\
\hline $\mathbf{2 0 1 3}$ & 0 \\
\hline $\mathbf{2 0 1 4}$ & 0 \\
\hline $\mathbf{2 0 1 5}$ & 0 \\
\hline $\mathbf{2 0 1 6}$ & 0 \\
\hline TOTAL & 610.356 \\
\hline
\end{tabular}

Quadro 2 - Quantidade de pessoas afetadas pelos desastres naturais na microrregião do Cariri paraibano, 2003 a 2016. Fonte: SEDEC, 2016 - Organização: Autor, 2017.

Além de causarem enorme prejuízo econômico, os danos materiais podem afetar toda a vida da população atingida, os danos causados as estradas e vias, por exemplo, podem prejudicar toda a logística dos itens básicos necessários para a sobrevivência da população. Dentre as unidades afetadas pelos desastres naturais, o maior prejuízo encontra-se nas estradas (com 5.022,9 km afetados) que foram destruídas ou danificadas principalmente pelos desastres de ordem hidrometeorológica (Quadro 3). 


\begin{tabular}{|c|c|c|}
\hline Unidade Afetada & Destruídas & Danificadas \\
\hline Instituições Públicas de Saúde & 0 & 0 \\
\hline Instituições Públicas de Ensino & 7 & 0 \\
\hline $\begin{array}{c}\text { Instituições Públicas Prestadoras } \\
\text { de outros serviços }\end{array}$ & 0 & 0 \\
\hline $\begin{array}{c}\text { Instituições Públicas de uso } \\
\text { Comunitário }\end{array}$ & 0 & 0 \\
\hline Unidades Habitacionais & 313 & 453 \\
\hline Obras de Infraestrutura Públicas & 0 & 0 \\
\hline Obras de Arte (Quantidade) & 11 & 42 \\
\hline Estradas (Km) & 462 & $4.560,9$ \\
\hline Pavimentação de vias urbanas (mil m ${ }^{2}$ ) & 0 & 0 \\
\hline Particulares de Saúde (Quantidade) & 0 & 0 \\
\hline Particulares de Ensino (Quantidade) & 0 & 0 \\
\hline Rurais/Açude (Quantidade) & 85 & 315 \\
\hline Industriais & 21 & 0 \\
\hline Comerciais & 0 & 0 \\
\hline
\end{tabular}

Quadro 3 - Unidades destruídas e danificadas pelos desastres naturais na região do Cariri paraibano, 2003 a 2016.

Houve uma grande dificuldade com a análise dos prejuízos econômicos, mas nos que estavam passíveis de análise foi identificado um prejuízo de $\mathrm{R}$ 13.236.000 (treze milhões duzentos e trinta e seis mil reais).

\section{CONSIDERAÇÕES FINAIS}

Constatou-se um grande número dos desastres oriundos das Secas e Estiagens na região do Cariri paraibano. No ano de 2004, atipicamente, a região sofreu maior incidência de desastres de ordem hidrometeorológica, mais precisamente chuvas intensas e enxurradas já nos anos de 2003 e 2013 os desastres de maior ocorrência foram de ordem climática, secas e estiagens, sendo este último coincidente com o início do período de seca no NEB.

Constatou-se que na região do Cariri paraibano, entre os anos de 2003 e 2016, foram reconhecidos um total de 604 desastres, desses, 548 foram reconhecidos por meio de SE e 56 por meio de ECP, distribuídos em 558 secas/estiagem, 19 inundações, 16 enxurradas e 11 chuvas intensas.

A pesquisa teve cunho descritivo e não se encerra com os resultados já obtidos, continuará com a análise e correlação dos fenômenos com a dinâmica climática e variabilidade das chuvas na região do Cariri.

O trabalho cumpre sua função social em informar, a todos aqueles que se interessarem, os problemas que a má gestão dos recursos e a não prevenção podem causar a população. Fica então, o 
registro e a disponibilidade para o poder público de usar está pesquisa como critério de informação para entender os prejuízos que um desastre natural pode causar e de acordo com isso verificar as precações que podem tomar para diminuir estes danos.

\section{REFERÊNCIAS BIBLIOGRÁFICAS}

JUNGLES, A. E. et al. Atlas brasileiro de desastres naturais, 1991 A 2012. 2. ed. Florianópolis: CEPED UFSC, 2013. 5 p. Disponível em: <http://www.ceped.ufsc.br/wpcontent/uploads/2012/01/AMAZONAS_mioloWEB.pdf>. Acesso em: 23 maio 2017. 105 p.

MINISTÉRIO DA INTEGRAÇÃO NACIONAL. .: INSTRUÇÃO NORMATIVA No 01, DE 24 DE AGOSTO DE 2012. Brasília: 2012. 8 p. Disponível em: <http://www.mi.gov.br/c/document_library/get_file?uuid=822a4d42-970b-4e80-93f8daee395a52d1\&groupId=301094> . Acesso em: 05 abr. 2017.

MOURA, M. O. et al. Desastres hidrometeorológicos na região Nordeste do Brasil: distribuição espaço - temporal dos reconhecimentos de Estado de Calamidade Pública. Caderno de Geografia, Minas Gerais, v. 1, n. 2, p.1-13, 05 dez. 2016. Disponível em: <http://periodicos.pucminas.br/index.php/geografia/article/viewFile/13317/10533>. Acesso em: 25 maio 2017. 13 p.

NASCIMENTO, S. S.; ALVES, J. J. A. Ecoclimatologia do Cariri Paraibano. Revista Geogr. Acadêmica, Ano 2008, v.2. n.3. Campina Grande: 2008. 14 p.

SILVA, L. L.. Precipitações pluviais da pré-estação chuvosa no período chuvoso e suas influências na produtividade agrícola da Paraíba. Dissertação de mestrado apresentado ao Programa de Pós Graduação em Meteorologia da Universidade Federal de Campina Grande, 2007. $114 \mathrm{p}$.

TOMINAGA, L. K.; SANTORO, J.; AMARAL, R. Desastres Naturais: conhecer para previnir. São Paulo: Instituto Geológico, 2009. 197 p.

Recebido em: 19/12/2017

Aceito para publicação em: 19/04/2018 